\title{
Cutaneous ulcer in an immunosuppressed patient with adult onset Still's disease: primary cutaneous histoplasmosis?
}

\author{
Michelle Larissa Zini Lise ${ }^{1}$ \\ Flávia Moojen Brollo ${ }^{1}$
}

Ronaldo Nunes Godinho
Henrique Luiz Staub

DOI: http://dx.doi.org/10.1590/abd1806-4841.20142727

Abstract: Histoplasmosis is caused by the dimorphic fungus Histoplasma capsulatum.Primary infection occurs through inhalation of spores from the air. Immunocompetent individuals are usually asymptomatic, but may develop pulmonary disease. Immunocompromised patients tend to present systemic histoplasmosis with cutaneous lesions occurring by secondary invasion. In this case report, we describe a probable primary cutaneous histoplasmosis $(\mathrm{PCH})$ in a patient with adult onset Still's disease under immunosuppression.

Keywords: Histoplasmosis; Immunocompromised host; Still's disease, adult-onset

Histoplasmosis is a major cause of endemic mycosis worldwide. Immunosuppressed patients tend to present severe systemic disease. ${ }^{1}$ We herein report a case of an immunocompromised patient with adult onset Still's disease (AOSD) who, interestingly, developed a probable primary cutaneous histoplasmosis $(\mathrm{PCH})$.

The patient, a 44-year-old white female, has presented features compatible with AOSD since February 2011 (spiking fever, morbilliform rash, arthromialgia, cervical lymphadenopathy, pleuropericarditis, leukocytosis, hemolytic anemia and hyperferritinemia). The bone-marrow biopsy showed no malignancy. While on use of prednisone $35 \mathrm{mg}$ and leflunomide $20 \mathrm{mg}$ daily, in December 2011, the patient developed a non-tender deep ulceration of 2.5 $\mathrm{cm}$ in the posteromedial aspect of the left lower limb (Figure 1). The patient reported to live near a chicken farm. The ulcer was not responsive to cephalosporin, and a skin biopsy was carried out. The histological findings included a lymphocytic and neutrophilic infiltrate with foci of necrosis; spores of Histoplasma capsulatum were seen on direct mycological exam (Grocott staining showing black intracitoplasmatic structures in macrophages (Figure 2). The chest radiogram was normal. Abdominal echography was unre- markable. Serum levels of sodium, potassium, creatinine and liver enzymes were all normal. Leflunomide was then withdrawn. After 6 months of therapy with itraconazol $300 \mathrm{mg}$ daily, the skin ulcer healed. The patient has been monitored for about 18 months now, with no recurrence or other feature of histoplasmosis.

Histoplasmosis is an opportunistic infection in compromised T-cells hosts. Hematogenous dissemi-

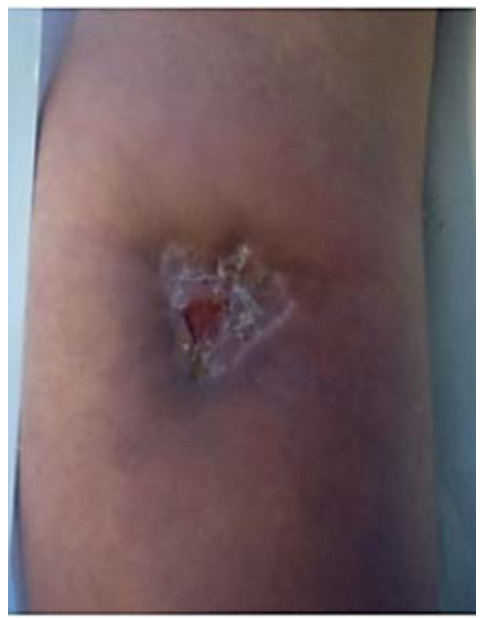

Figure 1:

Deep ulceration of $2.5 \mathrm{~cm}$ in the posteromedial lower limb District, Brasil

Received on 29.04.2013.

Approved by the Advisory Board and accepted for publication on 01.07.2013.

Study conducted at the Rheumatology Outpatient Clinic of the São Lucas Hospital of the Pontifical Catholic University of Rio Grande do Sul (PUC-RS) - Porto Alegre (RS), Brazil.

Financial Support: None

Pontifícia Universidade Católica do Rio Grande do Sul (PUC-RS) - Porto Alegre (RS), Brazil. 


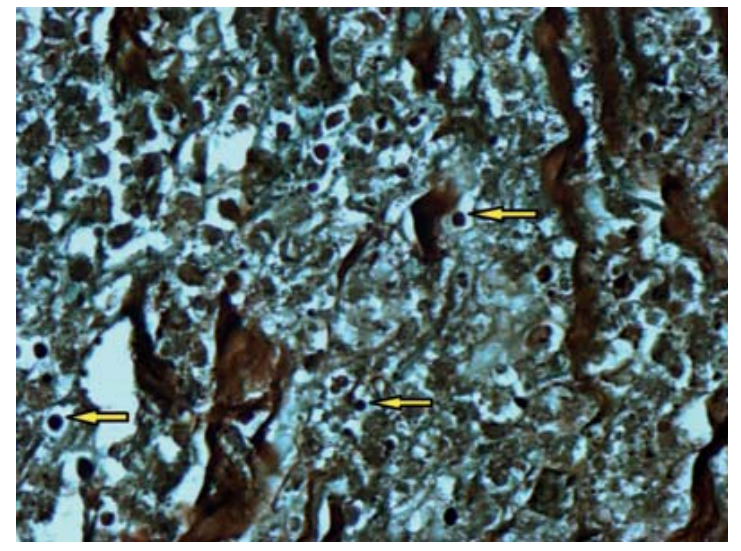

FIGURE 2: Histological section showing fungal intracellular and extracellular forms in Grocott 1000x magnification. Arrows show the fungi

nation generally occurs early in the course of disease, and dermatologic findings are seen in approximately $10 \%$ of cases. Lesions such as erythematous or hyperpigmented papules, pustules, ulcerations, erythema multiforme, and rosacea-like rashes develop by secondary spread. ${ }^{2}$ In our immunocompromised patient with AOSD, a disseminated form of histoplasmosis would be a more plausible presentation, but unexpectedly a $\mathrm{PCH}$ turned out to be probably the case.

$\mathrm{PCH}$, first described by Curtis \& Cawley in 1947 , is a very rare form of histoplasmosis. It is meant to occur by direct implantation of the agent into the skin. ${ }^{3}$ Although $\mathrm{PCH}$ has been well described in immunocompetent individuals, an increasing number of reports have accounted for the occurrence of $\mathrm{PCH}$ in immunocompromised adults, including in cases of diabetes mellitus. ${ }^{4-6}$ The only description of $\mathrm{PCH}$ in a rheumatic autoimmune disorder dates from 2000, when a patient with rheumatoid arthritis on long- standing corticotherapy developed, like the patient in this study, an ulcerative form of the disease. ${ }^{7}$

Thus, this may probably be the first case of $\mathrm{PCH}$ in an immunocompromised patient with AOSD. AOSD was confirmed by the presence of distinctive clinical and laboratory features in our patient. ${ }^{8}$ The $\mathrm{PCH}-$-related skin ulcer appeared during immunosuppressive therapy with steroids and leflunomide.

Knowingly, cutaneous lesions related to histoplasmosis usually occur by hematogenic dissemination, and a quarter of patients with systemic disease have, as seen in our patient, normal chest radiogram. Therefore, mucocutaneous manifestations should be considered, at least initially, as part of a disseminated form of the disease. ${ }^{9}$ Indeed, the classification of cutaneous histoplasmosis in primary or secondary to subclinical systemic disease can be very subtle, as shown in a recent case report. ${ }^{10}$ We emphasize, nevertheless, that our patient with cutaneous ulcer showed no obvious features of systemic histoplasmosis. Long duration therapy with itraconazol was highly effective.

Of interest, direct mycological analysis of the skin specimen using the Grocott stain was confirmatory for histoplasmosis in our patient. Even though a nested polymerase chain reaction (PCR) has been reported as a highly effective method for early diagnosis of histoplasmosis in HIV positive patients, the Grocott stain was as sensitive as the nested PCR for detection of Histoplasma capsulatum in spleen of infected mice. ${ }^{11,12}$

In summary, we here describe a case of probable $\mathrm{PCH}$ in a patient with AOSD using steroids and leflunomide. An increasing number of cases of $\mathrm{PCH}$ are being reported in patients with immunodeficiency or under immunosuppressive therapy. We bring the need for histological and mycological examination of suspicious skin lesions in patients under these circumstances. $\square$ 


\section{REFERENCES}

1. Knox KS, Hage CA. Histoplasmosis. Proc Am Thorac Soc. 2010;7:169-72

2. Wheat LJ, Kauffman CA. Histoplasmosis. Infect Dis Clin North Am. 2003;17:1-19, vii.

3. Curtis AC, Cawley EP. Genital histoplasmosis. J Urol. 1947;57:781-7.

4. Saheki MN, Schubach Ade 0, Salgueiro Mde M, Conceição-Silva F, Wanke B, Lazera M. Primary cutaneous histoplasmosis: case report on an immunocompetent patient and review of the literature. Rev Soc Bras Med Trop. 2008:41:680-2.

5. Buitrago MJ, Gonzalo-Jimenez N, Navarro M, Rodriguez-Tudela JL, Cuenca-Estrella M. A case of primary cutaneous histoplasmosis acquired in the laboratory. Mycoses. 2011;54:e859-61.

6. Krunic AL, Carag H, Medenica MM, Lorincz AL. A case of primary cutaneous histoplasmosis in a patient with diabetes and multiinfarct dementia. J Dermatol. 2002;29:797-802.

7. Romano C, Castelli A, Laurini L, Massai L. Case report. Primary cutaneous histoplasmosis in an immunosuppressed patient. Mycoses. 2000;43:151-4

8. Bagnari V, Colina M, Ciancio G, Govoni M, Trotta F. Adult onset Still's disease. Rheumatol Int. 2010;30:855-62.

9. Kauffman CA. Histoplasmosis: a clinical and laboratory update. Clin Microbiol Rev. 2007;20:115-32.

10. Norgan AP, Berbari EF, Roberts GD, Pritt BS.A 79-year-old man with swelling and crusted cutaneous ulceration of both hands.Clin Infect Dis. 2010;50:871,933-4

11. Dantas KC, Freitas RS, Moreira AP, Silva MV, Benard G, Vasconcellos C, et al. The use of nested Polymerase Chain Reaction (nested PCR) for the early diagnosis of Histoplasmacapsulatum infection in serum and whole blood of HIV positive patients. An Bras Dermatol. 2013;88:141-3.

12. Bialek R, Ernst F, Dietz K, Najvar LK, Knobloch J, Graybill JR, et al. Comparison of staining methods and a nested PCR assay to detect Histoplasmacapsulatum in tissue sections. Am J Clin Pathol. 2002;117:597-603.

\author{
MAILING ADDRESS: \\ Michelle Larissa Zini Lise \\ Av. Ipiranga, 6690 - Partenon \\ 90160-090 - Porto Alegre - RS \\ Brazil \\ E-mail:dramizini@yahoo.com.br
}

How to cite this article: Lise MLZ, Godinho RN, Brollo FM, Staub HL. Cutaneous ulcer in an immunosuppressed patient with adult onset Still's disease: primary cutaneous histoplasmosis? An Bras Dermatol. 2014;89(3):532-4. 